\title{
Probing High Order Structure of Proteins by Fast-Atom Bombardment Mass Spectrometry
}

\author{
Yaoqing Liu and David L. Smith \\ Department of Medicinal Chemistry, Purdue University, West Lafayette, Indiana, USA
}

\begin{abstract}
During the past decade, numerous investigations have demonstrated that the rate at which amide hydrogens located at peptide linkages undergo isotopic exchange is a sensitive probe of the high order structure and dynamics of proteins. The present investigation demonstrates that microbore high-performance liquid chromatography (HPLC) continuous-flow fast-atom bombardment mass spectrometry (FABMS) can be used to accurately quantify deuterium located at peptide linkages in short segments of large proteins. This result is important because it demonstrates the feasibility of using mass spectrometry as a tool for studying the high order structure and dynamics of large proteins. Following a period of deuterium exchange-in, a protein was placed into slowexchange conditions and fragmented into peptides with pepsin. The digest was analyzed by continuous-flow HPLC FABMS to determine the molecular weights of the peptides, from which the number of deuterons located at the peptide linkages could be deduced. The HPLC step was used both to fractionate the peptides according to their hydrophobicities and to remove through backexchange all deuterium except that located at peptide amide linkages. This approach has been applied to $\alpha$-crystallin, a lens protein composed of two gene products with monomer molecular weights of $20 \mathrm{kDa}$ and an aggregate molecular weight approaching $1000 \mathrm{kDa}$. Results from this study show that some of the peptide amide hydrogens in aA-crystallin exchange very rapidly $\left(\mathrm{k}>10 \mathrm{~h}^{-1}\right)$ while others exchange very slowly $\left(\mathrm{k}<10^{-3} \mathbf{h}^{-1}\right)$. The ability not only to detect that a conformational change has occurred, but also to identify the specific regions within the protein where the change occurred, was demonstrated by measuring changes in the exchange rates within these regions as the deuterium exchange-in temperature was increased from 10 to $80{ }^{\circ} \mathrm{C}$. (J Am Soc Mass Spectrom 1994, 5, 19-28)
\end{abstract}

$\mathrm{O}$ ver the past ten years, mass spectrometry has become an efficient and often essential tool for determining the primary structures of proteins. However, protein function is determined primarily by high order structure, which includes secondary, tertiary, and, for some proteins, quaternary structure. In principle, high order structures of proteins can be deduced from their primary structures. However, because proteins are made up of as many as 20 diflerent amino acids whose interactions are not fully defined at this time, accurate prediction of high order structures of proteins from their primary structures remains a distant goal. As a result, $x$-ray crystallography and NMR spectroscopy are playing an important role in linking the primary structures of proteins with their functions. Very recently, mass spectroscopists have turned their attention to the high order structures of proteins. For example, bimodal charge distributions in electrospray ionization mass spectra of proteins have been attributed to the presence of different conformations in solution, each conferring a different accessibil-

Address reprint requests to Professor David L. Smith, Department of Medicinal Chemistry, Purdue University, West Lafayette, IN 47907. ity of basic residues to the solvent [1-3]. In addition, Katta and Chait [4] demonstrated that methanol denatures bovine ubiquitin, exposing labile hydrogens to deuterated solvent and facilitating their isotopic exchange. Similarly, Winger et al. [5] showed that hydrogen isotopic exchange in the gas phase may be used to distinguish between proinsulin and reduced proinsulin.

Despite Ule undisputed success of $x$-ray spectroscopy, our understanding of the structure/function relationships of many proteins remains incomplete because of limitations inherent to current analytical methods. Amide hydrogen exchange, another method for probing the high order structure and dynamics of proteins, has been used to enhance our understanding of crystallographic structures [6-10]. It is potentially useful for structure/function investigations of proteins that cannot be crystallized. When compared with other spectroscopic methods that sense environmental changes around specific types of residues (e.g., tryptophan phosphorescence), hydrogen exchange is a particularly useful probe of protein structure because there are sensors at each peptide amide linkage, except for those where proline furnishes the amide nitrogen. $\mathrm{Hy}$ drogen exchange can be used as a probe of protein 
structure and dynamics only if the rate at which the amide hydrogens undergo exchange can be measured.

Many peptide amide hydrogens participate in a complex network of intramolecular hydrogen bonds throughout proteins, thereby playing an important role in stabilizing their high order structures. As proteins change conformation, the network of hydrogen bonds may be altered, causing changes in the rates at which amide hydrogens undergo isotopic exchange. For example, an $\alpha$-helix or a $\beta$-sheet may become partially unfolded, increasing the exposure of the amide hydrogens to solvent and facilitating isotopic exchange. If the rates at which peptide amide hydrogens undergo isotopic exchange in specific regions of a protein can be determined, hydrogen exchange may be used as a probe to identify those regions involved in conformational changes. This type of regional-specific information is required to understand the relation between protein structure and function.

Several different instrumental methods have been used to detect and quantify hydrogen exchange in proteins. Early investigations simply determined the rate at which tritium exchanged into or out of proteins $[11,12]$. Similarly, Fourier transform infrared (FTIR) and UV spectroscopies have been used to determine the total rate at which peptide amide hydrogens in proteins are replaced with deuterium $[13,14]$. These methods are similar to changes in charge patterns observed with electrospray mass spectrometry in that they can be used to show that structural changes have occurred. In general, these methods cannot be used to locate specific regions changing conformation within a protein. Regional-specific conformational changes have been detected by amide hydrogen exchange measurements in which one- and two-dimensional NMR spectroscopy was used to determine hydrogen exchange rates at specific peptide amide linkages in several small proteins [6-10]. For example, this approach was used to study hydrogen exchange in bovine pancreatic trypsin inhibitor [6] and in its complexes [7], to characterize cytochrome $c$ under a variety of conditions [8, 9], and to test for the presence of nonrandom structure in thermally denatured ribonuclease $A$ [10].

We report a new method, based on fast-atom bombardment mass spectrometry (FABMS) and protein fragmentation, which can be used to determine accurately hydrogen exchange rates that differ by as much as four orders of magnitude within small and specific regions of large proteins. The ability to detect regional-specific changes in protein structure by this method was demonstrated by measuring deuterium exchange into a protein at different temperatures. This approach has roots in studies described by Rosa and Richards [15] and Englander et al. [16, 17], who determined hydrogen exchange rates by exchanging tritium into proteins, fragmenting the proteins into peptides, separating the peptides by high-performance liquid chromatography (HPLC), and quantifying the tritium in the peptides. We have used deuterium in place of tritium and quantified its incorporation by directly coupled continuous-flow HPLC FABMS. Our results demonstrate that these modifications to the protein fragmentation method are a significant advance in methodology, facilitating widespread use of hydrogen exchange as a probe of the high order structure and dynamics of proteins. Application of this approach to cytochrome $c$, a small protein of $M_{r} 12 \mathrm{kDa}$, has been described [18]. We report here the application of this approach to $\alpha$-crystallin, an aggregate protein with $M_{r}$ approaching $1000 \mathrm{kDa}$.

\section{Experimental}

\section{Reagents}

Pepsin, carboxypeptidase $Y$, anhydrous monobasic sodium phosphate, monothioglycerol (Sigma C'hemical Co., St. Louis, MO); anhydrous dibasic sodium phosphate, glycerol (Mallinckrodt, Inc., Paris, KY); and deuterium oxide (Aldrich Chemical Co., Milwaukee, WI) were used without further purification.

\section{$\alpha$-Crystallin Isolation}

Bovine lenses from 2-year-old cows, obtained from the Purdue University Animal Science Pilot Plant, were homogenized in $0.5 \mathrm{M} \mathrm{NaCl} / 0.05 \mathrm{M}$ TRIS/0.001 M EDTA buffer ( $\mathrm{pH} 7.4$ ) for $1 \mathrm{~h}$. The supernatant present after centrifuging for $1 \mathrm{~h}$ at $15,000 \mathrm{~g}$ was fractionated by gel filtration chromatography (Sephadex G-200, Pharmacia, Piscatway, NJ) to give four peaks, designated $\alpha-, \beta_{\mathrm{H}^{-}}, \beta_{\mathrm{L}^{-}}$, and $\gamma$-crystallin [19]. The $\alpha$-crystallin fraction was dialyzed against $\mathrm{H}_{2} \mathrm{O}$, lyophilized, and stored at $-20^{\circ} \mathrm{C}$.

\section{Isotope Exchange}

Deuterium was exchanged into $\alpha$-crystallin by dissolving 10 nmole of protein in $10 \mu \mathrm{L}$ of buffer solution $\left(\mathrm{Na}_{2} \mathrm{HPO}_{4} / \mathrm{D}_{2} \mathrm{O}_{r} \mathrm{pD}\right.$ 7.2) and incubated for different times and temperatures. Fully deuterated $\alpha$-crystallin was prepared by incubating the protein in $\mathrm{D}_{2} \mathrm{O}$ for $4 \mathrm{~h}$ at $80{ }^{\circ} \mathrm{C}$ and $\mathrm{pD}$ 7.2. The exchange reaction was quenched by adding $2 \mu \mathrm{L}$ of $0.5 \mathrm{M} \mathrm{DCl}$, lowering the $\mathrm{pD}$ to 2.5. The protein was fragmented into peptides by digesting with pepsin (substrate:enzyme 5:1) for 10 min at $0^{\circ} \mathrm{C}$. The digest was analyzed immediately by continuous-flow HPLC FABMS.

\section{Continuous-Flow HPLC FABMS}

The sample introduction system on the continuous-flow HPLC FAB mass spectrometer used to determine the molecular weights of partially deuterated peptides is illustrated in Figure 1. The chromatographic portion of the apparatus consisted of a gradient HPLC system (Rainin Instrument Co., Woburn, MA), a high pressure injector with a $10-\mu \mathrm{L}$ injection loop (Rheodyne model 


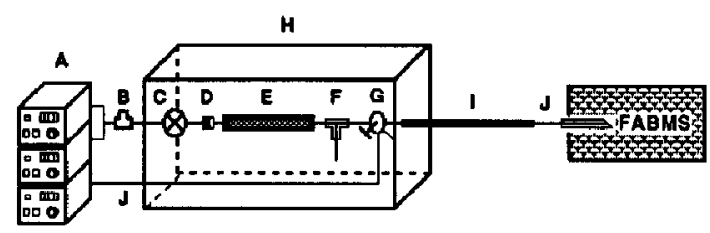

Figure 1. Continuous-flow microbore HPLC FABMS system used to analyze peptic digests of $\alpha$-crystallin. (A) HPLC pumps; (B) mixing tee; (C) injector; (D) precolumn filter; (E) 1-mm ID RP column; (F) effluent splitter; (G) ten-port valve; $(\mathrm{H})$ ice bath box; (I) ice water flow tube; (J) $50-\mu \mathrm{m}$ ID fused silica capillary. The entire HPLC system, including the fused silica transfer line, was placed in an ice bath to minimize loss of deuterium during analysis.

8125), a microbore reversed-phase column (Applied Biosystems, $1 \times 100 \mathrm{~mm}$ ), an effluent splitter, a ten-port valve (Valco C10U), and an additional HPLC pump (Rainin Instrument Co.). Buffer salts used in the incubation were diverted from the $F A B$ probe tip by the ten-port valve. To prevent drying of the probe tip while the effluent from the column was diverted, a third HPLC pump (Figure 1) was used to maintain a steady flow of $3 \mu \mathrm{L} / \mathrm{min}$ to the probe tip. Solvents $A$ and $\mathrm{C}$ were $\mathrm{H}_{2} \mathrm{O}$; solvent $\mathrm{B}$ was $50 \%$ acetonitrile. All solvents contained $3 \%$ glycerol, $3 \%$ thioglycerol, and $0.1 \%$ trifluoroacetic acid. Peptides were fractionated with a gradient from 0 to $60 \% \mathrm{~B}$ in $20 \mathrm{~min}$. The column effluent, $50 \mu \mathrm{L} / \mathrm{min}$, was split to $3 \mu \mathrm{L} / \mathrm{min}$ before introduction into the mass spectrometer. The entire chromatographic system, up to the continuous-flow probe, was immersed in an ice bath to minimize the loss of deuterium from the peptides during analysis. The continuous-flow probe has been described previously [20]. Mass spectral analyses were performed with a Kratos MS-50 RF mass spectrometer (Kratos Analytical, Ramsey, NJ), which was operated at 8-kV accelerating voltage and a scan rate of $30 \mathrm{~s} /$ decade. Data acquired with a Kratos DS-90 system were displayed with a Sun work station operating with Kratos MACH-3 software, and analyzed with software written in this laboratory [18]. Peptides from $\alpha$-crystallin were identified using procedures described previously [19].

\section{Results and Discussion}

$\alpha$-Crystallin, a major constituent of mammalian lenses, is composed of two gene products, $\alpha \mathrm{A}$ and $\alpha \mathrm{B}$ crystallin. The amino acid sequences of $\alpha \mathrm{A}$ - and $\alpha \mathrm{B}$-crystallin, as determined by van der Ouderaa et al. [21, 22], are presented in Figure 2. The primary structures of these proteins, including the sites of phusphorylation, have also been studied extensively by mass spectrometry $[23,24]$. Analysis of these proteins by circular dichroism indicated that their secondary structure is primarily $\beta$-sheet [25]. Although the molecular weights of the monomeric subunits of $\alpha$-crystallin' are only 20 $\mathrm{kDa}$, they aggregate to form chusters with molecular

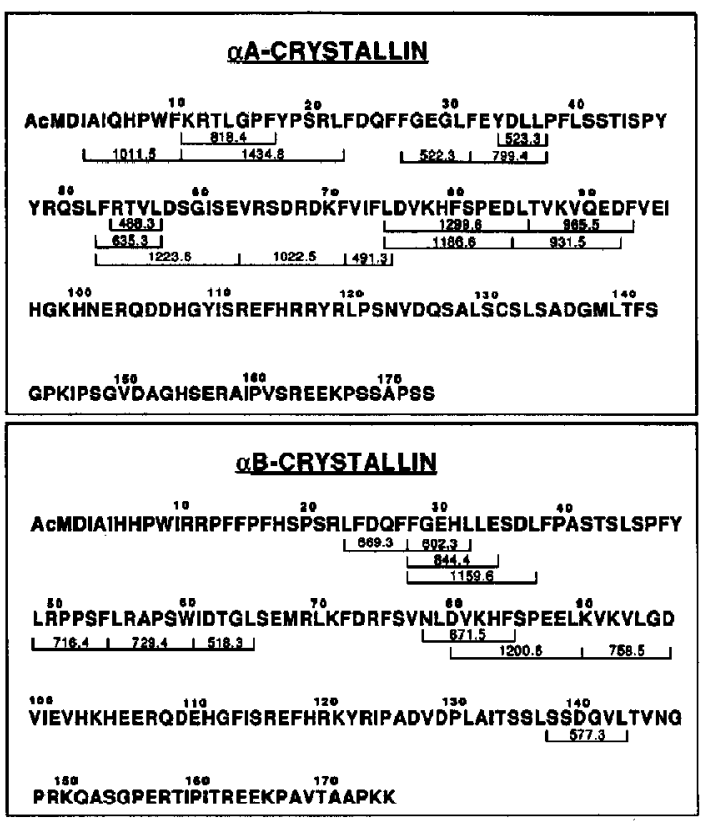

Figure 2. Amino acid sequences of $\alpha \mathrm{A}$ - and $\alpha \mathrm{B}$-crystallin [21, 22] indicating segments for which hydrogen exchange rate constants have been determined using the present experimental conditions.

weights approaching $1000 \mathrm{kDa}$. The quaternary structure of $\alpha$-crystallin has been the subject of several recent studies [26-29]. Since $\alpha$-crystallin has been resistant to crystallization and since it is much too large to be studied by high resolution NMR spectroscopy, it has been used in this study to explore hydrogen exchange as a probe of high order structure in large proteins.

\section{Deuterium Exchange-in}

The mechanism for hydrogen exchange involves an intermediate complex in which the hydrogen is shared between the peptide and a hydrogen exchange catalyst, such as $\mathrm{OH}^{-}$or $\mathrm{H}_{3} \mathrm{O}^{+}$. As the intermediate complex dissociates, the hydrogen may remain with the catalyst and be replaced on the peptide by hydrogen (deuterium) from the solvent. The rate constant for hydrogen exchange, $\mathrm{k}_{e x}$, is given by the expression:

$$
\mathbf{k}_{\mathrm{ex}}=\mathrm{k}_{\mathrm{OH}}\left[\mathrm{OH}^{-}\right]+\mathbf{k}_{\mathrm{H}}\left[\mathrm{H}^{+}\right]
$$

where $\mathrm{k}_{\mathrm{OH}}$ and $\mathrm{k}_{\mathrm{H}}$ are the rate constants for base and acid-catalyzed hydrogen exchange. The $\mathrm{pH}$ dependence of $\mathbf{k}_{\mathrm{ex}}$ for amide hydrogens in polyalanine is illustrated in Figure 3, which shows that the minimum exchange occurs at $\mathrm{pH} 3[11,30]$. The dependence of $k_{\text {ex }}$ on the inductive effect of adjacent amino acid side chains effectively expands the minimum for exchange in peptides over the $\mathrm{pH}$ range 2 to 3 [31]. For neutral 


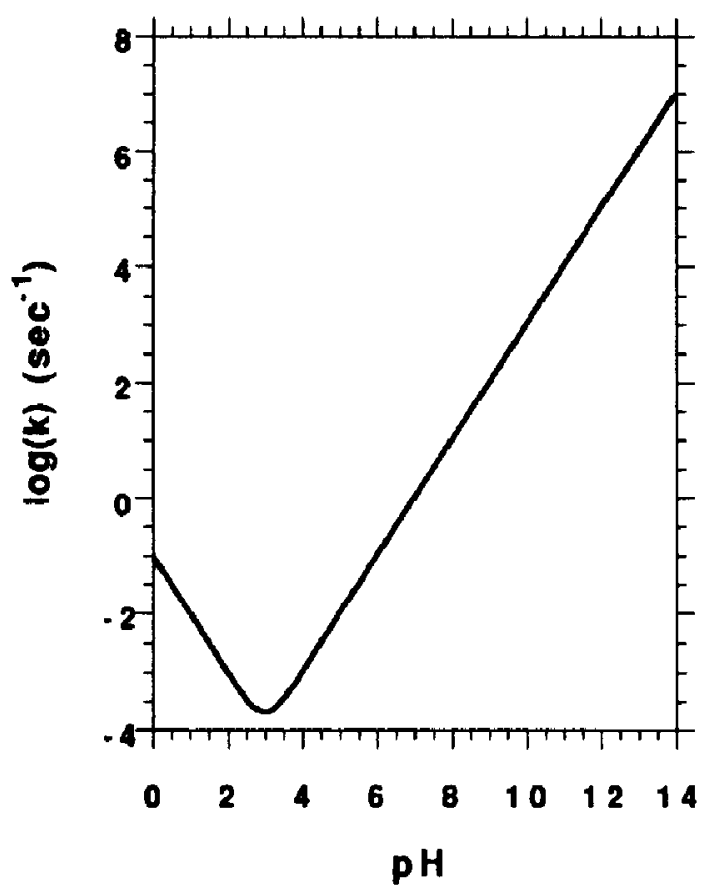

Figure 3. Illustration of the pII dependence of the rate constant for isotopic exchange of amide hydrogens in polyalanine [11,30].

or alkaline $\mathrm{pH}$, rate constants for isotopic exchange of amide hydrogens in small peptides depend primarily on the $\mathrm{pK}_{\mathrm{a}} \mathrm{s}$ of the amide hydrogens. In large peptides and proteins, isotopic exchange of peptide amide hydrogens may be reduced by several orders of magnitude, either because they are hydrogen bonded to other parts of the molecule or because they have limited access to the solvent and hydrogen exchange catalysts. This reduction in exchange rate facilitates hydrogen exchange as a probe of high order structure in proteins [30].

The basis of the protein fragmentation method [15, $16]$, as used in the present investigation, can be described with the aid of Figures 3 and 4. Deuterium is exchanged into the protein at high $\mathrm{pH}$ where the intrinsic rate of hydrogen exchange is fast, as indicated in Figure 3 . The actual rate of exchange depends on the high order structure of the protein, and may be fast or slow. After the desired exchange-in time, the amide hydrogen exchange reaction is quenched by lowering the $\mathrm{pH}$ to 2.5 and decreasing the temperature to $0{ }^{\circ} \mathrm{C}$. A brief digestion with an acid protease, such as pepsin, fragments the protein into peptides that are analyzed immediately by directly coupled HPLC FABMS to determine their deuterium contents. Under these conditions, the half-life for isotopic exchange of amide hydrogens in an unstructured peptide is approximately $50 \mathrm{~min}[31,32]$, suggesting that analysis may be completed before extensive back-exchange has occurred.

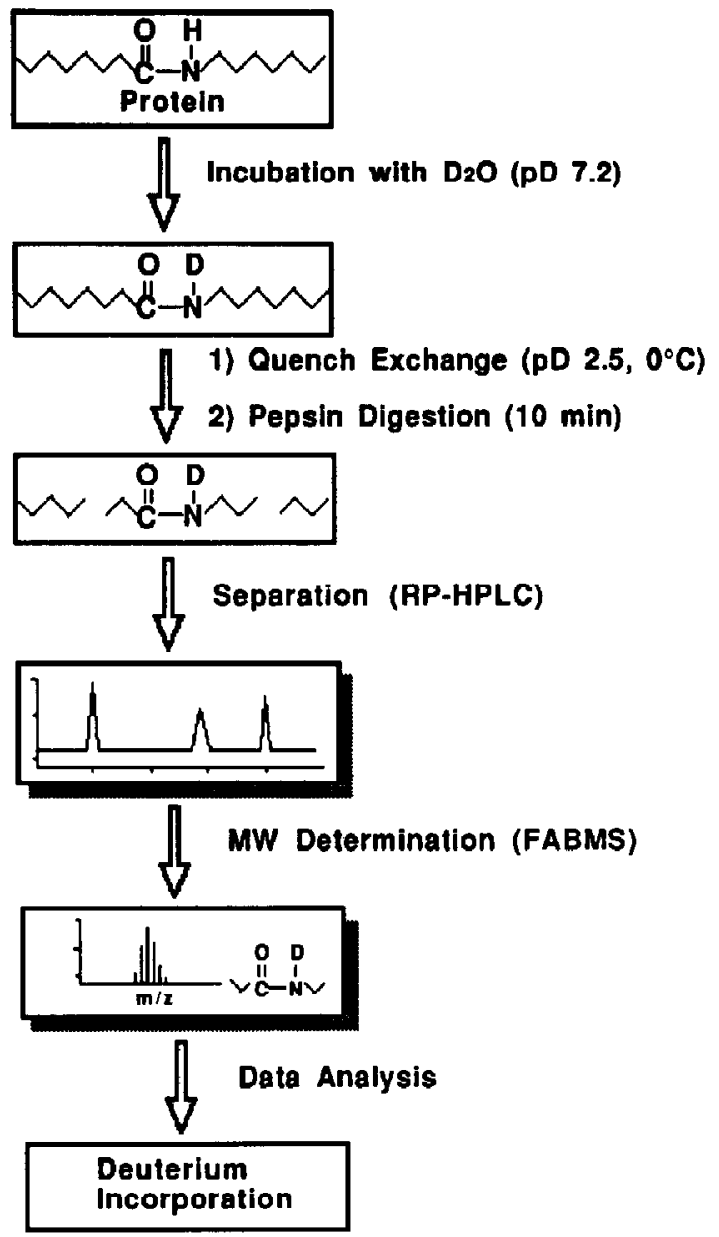

Figure 4. Steps used in the present procedure to determine the rates of hydrogen exchange in proteins. Following deuterium exchange-in, the protein was placed in slow-exchange conditions, fragmented into peptides, and analyzed by continuous-flow HPLC FABMS.

During the exchange-in period, peptide amide hydrogens as well as hydrogens on many other functionalities (e.g., $-\mathrm{OH},-\mathrm{NH}_{2}$ ) undergo isotopic exchange. The number of peptide amide deuterons can be determined directly from the molecular weight of the peptide because the analysis time is sufficient for backexchange for all but the deuterons located at the peptide amide positions. They exchange much slower than the other exchangeable hydrogens. For example, under quench conditions, the half-life for exchange of peptide amide hydrogens is approximately 50 min $[31,32]$, while exchange of hydroxyl hydrogens is complete within seconds [30]. Since the elution time on reversed-phase HPLC is several minutes for even the most hydrophilic peptides, there is adequate time for all but the peptide amide deuterons to revert back to protium. As a result, the increase in molecular weight 
of deuterated peptides is a direct measure of the number of deuterons located at peptide amide linkages. In addition to providing conditions for removing all but the deuteriums of interest, fractionation of the digest by reversed-phase HPLC also improves the FABMS response, because these digests contain a large number of peptides with a wide range of hydrophobicities. Continuous-flow HPLC FABMS-selected ion plots obtained for four representative peptides in a peptic digest of partially deuterated $\alpha$-crystallin are illustrated in Figure 5. Two peptides $\left(\alpha A^{32-37}\right.$ and $\alpha A^{53-57}$ ) were from the A-chain, and two peptides $\left(\alpha B^{55-60}\right.$ and $\alpha B^{90-96}$ ) were from the $B$-chain of $\alpha$-crystallin. These plots were made by combining the intensities of the most abundant isotopic peaks comprising the molecular ion envelope of isotopic peaks. Chromatographic parameters were chosen so that the entire analysis was completed within $20 \mathrm{~min}$. For these conditions, three to five scans were obtained for each chromatographic peak.

The molecular ion region of the FAB mass spectrum of $\alpha \mathrm{A}^{75-85}$ is given in Figure $6(\mathrm{a}-\mathrm{d})$ for $\alpha$-crystallin prepared for analysis in different ways. The spectrum in Figure 6a, obtained for $\alpha$-crystallin that was neither incubated nor digested in $\mathrm{D}_{2} \mathrm{O}$, illustrates the natural abundance of heavy isotopes for this peptide. The FAB mass spectrum of the same peptide derived from $\alpha$ crystallin that was not incubated in $\mathrm{D}_{2} \mathrm{O}$, but was digested in $\mathrm{D}_{2} \mathrm{O}$, is given in Figure $6 \mathrm{~b}$. This spectrum illustrates the number of amide deuterons that exchanged into this peptide during the brief digestion of the protein. The spectrum in Figure $6 \mathrm{c}$ is for $\alpha$-crystallin that was incubated in $\mathrm{D}_{2} \mathrm{O}$ for $1 \mathrm{~h}$ and digested in $\mathrm{D}_{2} \mathrm{O}$. This sample is typical of samples that were analyzed to determine the rates of hydrogen exchange.

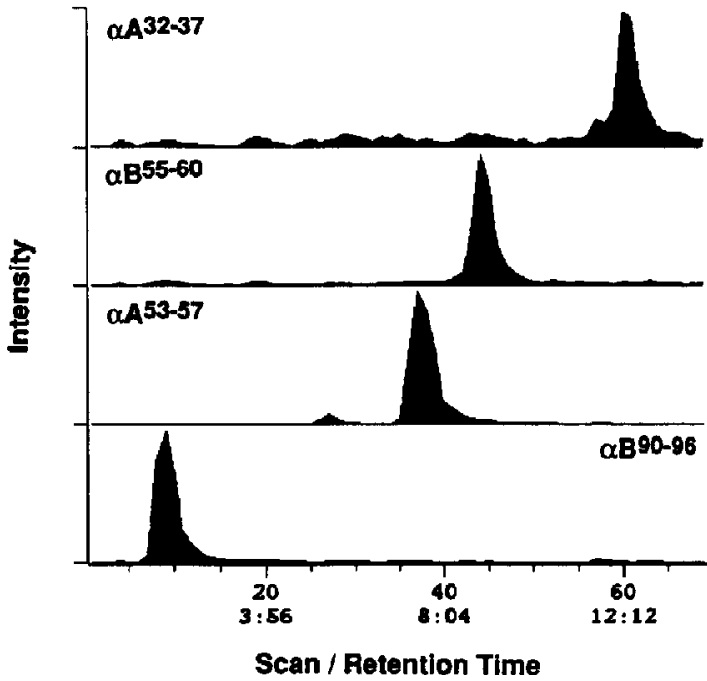

Figure 5. Continuous-flow HPLC FABMS-selected ion plots of four peptides $\left(\alpha \mathrm{A}^{32-37} ; \alpha \mathrm{B}^{55-60} ; \alpha \mathrm{A}^{53-57} ; \alpha \mathrm{B}^{90-96}\right)$ present in a peptic digest of partially deuterated $\alpha$-crystallin. The most abundant isotope peaks were summed and plotted for each peptide.

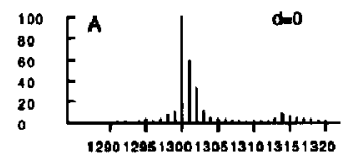

$\mathrm{m} / \mathbf{z}$
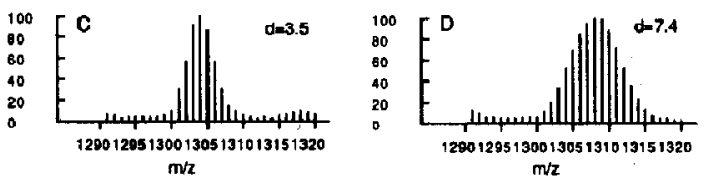

Figure 6. Molecular ion region of the continuous-flow FAB mass spectrum of $\alpha A^{75-85}$ detected in peptic digests of $\alpha$-crystallin. (a) $\alpha$-Crystallin incubated and digested in $\mathrm{H}_{2} \mathrm{O}$; (b) $\alpha$-crystallin incubated in $\mathrm{H}_{2} \mathrm{O}$ and digested in $\mathrm{D}_{2} \mathrm{O}_{;}$(c) a-crystallin incubated in $\mathrm{D}_{2} \mathrm{O}$ for $1 \mathrm{~h}$ and digested in $\mathrm{D}_{2} \mathrm{O}$; (d) completely deuterated $\alpha$-crystallin digested in $\mathrm{D}_{2} \mathrm{O}$. When adjusted for the natural abundance of isotopes (spectrum a), spectra b through d show that this peptide had $1.6,3.5$, and 7.4 deuterons, respectively.

To account for loss of deuterium during digestion and analysis, a sample of fully deuterated $\alpha$-crystallin was analyzed by the same procedure. The molecular ion region of the $\alpha \mathrm{A}^{75-85}$ peptide derived from fully deuterated $\alpha$-crystallin is given in Figure 6d. The number of amide deuterons in the $\alpha A^{75-85}$ peptides from $\alpha$-crystallin prepared in these different ways is given by the differences in the centroids of the molecular ion isotope patterns of the deuterated (Figure $6 b-d$ ) and nondeuterated (Figure 6a) peptides. Analysis of the spectra in Figure $6 \mathrm{~b}$ indicates that the nondeuterated $\alpha \mathrm{A}^{75-85}$ peptide acquired 1.6 deuterons during digestion. The spectrum in Figure $6 d$ shows that the $\alpha A^{75-85}$ peptide from fully deuterated $\alpha$-crystallin had 7.4 deuterons when it reached the mass spectrometer. This segment has 10 peptide linkages, but only 9 peptide amide hydrogens because it includes 1 proline residue. From the spectrum in Figure $6 \mathrm{~d}$, it follows that the $\alpha A^{75-85}$ peptide from fully deuterated $\alpha A$-crystallin lost 1.6 amide deuterons during analysis. This information was used to relate the number of deuterons present in $\alpha \mathrm{A}^{75-85}$ peptides derived from $\alpha$-crystallin incubated in $\mathrm{D}_{2} \mathrm{O}$ for varying times (e.g., Figure $6 \mathrm{c}$ ) to the number of deuterons that were present in the $\alpha A^{75-85}$ segment of $\alpha$-crystallin prior to digestion [18]. These adjustments were made by using eq 2

$$
\mathrm{D}_{0}=\frac{\langle\mathrm{m}\rangle-\left\langle\mathrm{m}_{0 \%}\right\rangle}{\left\langle\mathrm{m}_{100 \%}\right\rangle-\left\langle\mathrm{m}_{0 \%}\right\rangle} \mathrm{N}
$$

where $D_{0}$ is the average number of peptide amide deuterons in a particular segment of the protein after incubation in $D_{2} O$ for time $t,\left\langle m_{0 \%}\right\rangle$, and $\left\langle m_{100 \%}\right\rangle$ are the isotope-averaged centroids of the molecular ion peaks of the peptides derived from the completely 
protiated (Figure 6b) or deuterated protein (Figure 6d) standards, $\langle\mathrm{m}\rangle$ is the isotope-averaged centroid of the molecular ion peaks of the peptide from the protein that had been incubated in $\mathrm{D}_{2} \mathrm{O}$ for time $\mathrm{t}$ (Figure $6 \mathrm{c}$ ), and $\mathrm{N}$ is the number of peptide amide hydrogens in the peptide. Conceptually, the spectrum for a peptide with a natural abundance of isotopes (Figure 6a) should be subtracted from the spectra of partially deuterated peptides. However, because this adjustment must be made to each term in the numerator and denominator of eq 2, no adjustment for the natural abundance of isotopes is necessary. A complete derivation of this expression has been presented elsewhere [18]. For the results presented in Figure $6,\langle\mathbf{m}\rangle,\left\langle\mathrm{m}_{0 \%}\right\rangle$, and $\left\langle\mathrm{m}_{100 \%}\right\rangle$ are $3.5,1.6$, and 7.4 , respectively. When used with eq 2 , these results indicate that the $75-85$ segment of $\alpha \mathrm{A}$ had 2.9 deuterons after incubation in $\mathrm{D}, \mathrm{O}$ for $1 \mathrm{~h}$.

Peptides from $\alpha$-crystallin that was not incubated in $\mathrm{D}_{2} \mathrm{O}$ have a low level of deuterium because the digestion was performed in $\mathrm{D}_{2} \mathrm{O}$, while peptides from $\alpha$ crystallin that was fully deuterated are somewhat less than fully labeled because they lost some deuterium during HPLC analysis. To detect small changes in hydrogen bonding in proteins, the artifactual gain/loss of amide deuterium during analysis must be minimized. The amount of deuterium gained or lost during analysis depends on the $\mathrm{pH}$ and temperature of solutions used for digestion and HPLC fractionation, as well as on the peptide sequence and the initial level of deuteration. The magnitude of the adjustment (from eq 2) is smallest for peptides that are 40 to $60 \%$ labeled, and largest for peptides that have either very little deuterium or are fully deuterated. Although the extent of deuterium gain/loss during analysis depends on several factors, unlabeled peptides typically become $18 \%$ deuterated during analysis, and fully labeled peptides typically lose approximately $23 \%$ of their label, for these experimental conditions. It is important to note that the objective of most hydrogen exchange studies is to detect and locate conformational changes. For such applications, one is more interested in detecting a change in the number of deuterons present, which renders minor adjustments for gain/luss during analysis less important, as long as the experimental conditions used for analyses are identical.

\section{Hydrogen Exchange Rates}

The magnitude of the rate constant for base-catalyzed exchange of amide hydrogens in peptides (Figure 3) indicates that they undergo complete exchange in less than $1 \mathrm{~s}$ at $\mathrm{pD} 7.2$. Similarly, amide hydrogens in proteins that are neither hydrogen bonded nor shielded from the solvent exchange rapidly. However, amide hydrogens that are participating in intramolecular hydrogen bonding, as well as hydrogens buried in the hydrophobic interior of a protein, may require weeks or months to exchange [30]. This wide variation in amide hydrogen exchange rates is reflected in the deuterium exchange-in time course results presented in Figure 7, which is a plot of the percentage of peptide amide linkages that have been deuterated in two different segments $\left(\alpha \mathrm{A}^{53-63}\right.$ and $\alpha \mathrm{A}^{75-84}$ ) of $\alpha \mathrm{A}$-crystallin as a function of the time the protein was incubated in $D_{2} \mathrm{O}$. The levels of deuterium in these segments were determined using eq 2 and data similar to those presented in Figure 6. These results indicate that approximately $40 \%$ of the amide hydrogens in $\alpha \mathrm{A}^{53-63}$ were replaced with deuterium within $0.2 \mathrm{~h}$. After incubation in $\mathrm{D}_{2} \mathrm{O}$ for $48 \mathrm{~h}$, only $57 \%$ had undergone isotopic exchange. Similar results were found for $\alpha A^{75-84}$ where only one of the eight amide hydrogens underwent rapid exchange. After 48 - $\mathrm{h}$ incubation in $\mathrm{D}_{2} \mathrm{O}$, only three amide hydrogens in $\alpha \mathrm{A}^{75-84}$ were replaced with deuterium.

Although the rates at which specific amide hydrogens exchange cannot be deduced from these data, a more quantitative analysis is possible. The deuterium content of a peptide can be expressed as the sum of $\mathrm{N}$ terms, where each term represents the deuterium level at each of the $\mathrm{N}$ amide linkages. Exchange results for small peptides $(N<4)$ can be fitted to an expression containing specific rate constants for exchange at each of the amide positions. When applied to large peptides, this approach requires more variables and may lead to erroneous results. As a compromise, we have divided the amide hydrogens into three groups according to their rates of isotopic exchange [18]. Although the amide hydrogens in a particular group must have similar exchange rate constants, they may be located anywhere along the backbone of a peptide. The lines drawn through the experimental data points in Figure 7 represent the deuterium levels calculated for this three-component model by using eq 3

$$
\begin{aligned}
D= & N_{1}\left[1-\exp \left(-k_{1} t\right)\right] \\
& +N_{2}\left[1-\exp \left(-k_{2} t\right)\right]+N_{3} k_{3} t
\end{aligned}
$$

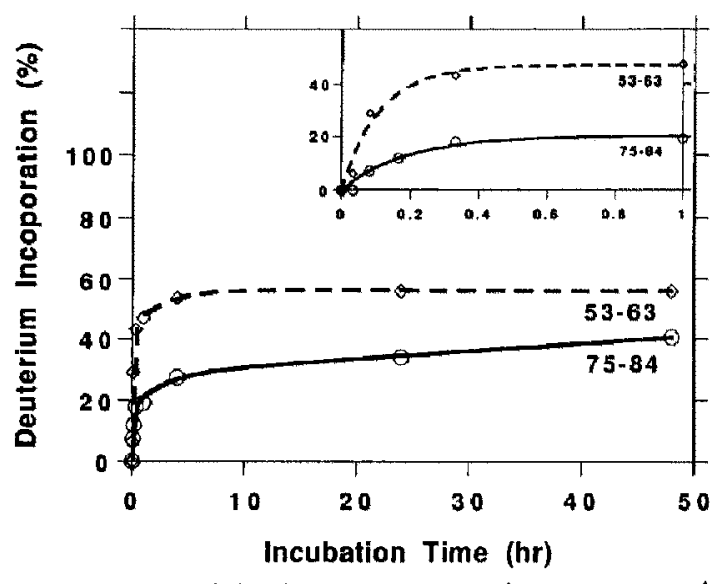

Figure 7. Plot of the deuterium content of two segments of $\alpha A$-crystallin $\left(\alpha A^{53-63}\right.$ and $\left.\alpha A^{75-84}\right)$, expressed as a percentage of peptide amide positions, as a function of the time allowed for deuterium exchange-in ( 2 min to $48 \mathrm{~h}$ ). 
According to this model, the total number of amide linkages in a peptide (N) is divided into three groups, $\mathrm{N}_{1}, \mathrm{~N}_{2}$, and $\mathrm{N}_{3}$, with exchange rate constants $\mathrm{k}_{1}, \mathrm{k}_{2}$, and $k_{3}$, respectively, for each group of amide hydrogens. Because the theoretical curves obtained using the three-component model fit the experimental data well, data analysis using more complex models is not justified.

Table 1 lists results obtained by applying the threecomponent model to exchange-in data for several peptides derived from $\alpha$-crystallin. Application of eq 3 to exchange-in data for $\alpha \mathrm{A}^{53-63}$ (Figure 7) shows that 4.4 of the amide hydrogens in this segment undergo isotopic exchange with rate constants of $9.9 \mathrm{~h}^{-1}$ or greater; 1.3 amide hydrogens exchange with an average rate constant of $0.4 \mathrm{~h}^{-1} ; 4.3$ hydrogens do not exchange on the time scale of this experiment $\left(\mathrm{k}<10^{-3} \mathrm{~h}^{-1}\right)$. These results indicate that approximately half $(4.4$ of 10$)$ of the amide hydrogens in the 53-63 segment of $\alpha \mathrm{A}$ crystallin exchange with half-lives of $4.2 \mathrm{~min}$ or less, while the other half have a half-lives equal to or greater than $693 \mathrm{~h}$.

These results demonstrate the reduction of peptide amide hydrogen exchange rates by the high order structure of $\alpha$-crystallin. If there were no high order structure to reduce the hydrogen exchange rate in $\alpha$-crystallin, the half-life for amide hydrogen exchange in $\alpha A^{53-63}$ would be approximately $1.3 \times 10^{-5} \mathrm{~h}$ at $\mathrm{pH} 7[11,31]$. It follows that the average half-life of the slowest exchanging amide hydrogens in this segment of the protein is at least $10^{7}$ longer than in the free peptide.

The ability to determine exchange rates for individual amide hydrogens (i.e., high spatial resolution) is the principal advantage of NMR spectroscopy for hydrogen exchange studies. The spatial resolution of the present method, which is limited primarily by the size of the peptides used, is generally not as good as that of NMR spectroscopy. The highest spatial resolution is achieved for regions of the protein that fragment to give small peptides. Spatial resolution may also be increased when overlapping peptides are available. For example, cleavage following Phe 74 combined with cleavage on either side of Leu 85 gives two overlapping peptides, $\alpha \mathrm{A}^{75-84}$ and $\alpha \mathrm{A}^{75-85}$. Because there is

Table 1. Results obtained by applying the three-component model to exchange-in data for peptides derived from $\alpha$-crystallin

\begin{tabular}{lcrrrrrr}
\hline Peptides & $\mathrm{N}_{1}$ & \multicolumn{1}{c}{$\mathrm{k}_{1}$} & $\mathrm{~N}_{2}$ & $\mathrm{k}_{2}$ & $\mathrm{~N}_{3}$ & \multicolumn{1}{c}{$\mathrm{k}_{3}$} & $\mathrm{~N}$ \\
\hline \hline $\mathrm{aA}^{53-63}$ & 4.4 & 9.9 & 1.3 & 0.4 & 4.3 & $<0.001$ & 10 \\
$\mathrm{aA}^{75-84}$ & 1.5 & 6.1 & 1.9 & 0.4 & 4.6 & 0.004 & 8 \\
$\mathrm{aA}^{75-85}$ & 2.5 & 10.7 & 1.9 & 0.4 & 4.6 & 0.002 & 9 \\
& & & & & & & \\
$\mathrm{aB}^{28-32}$ & 1.8 & $>10$ & 0.3 & 0.2 & 1.9 & 0.004 & 4 \\
$\mathrm{aB}^{28-34}$ & 1.8 & $>10$ & 0.4 & 0.5 & 3.8 & $<0.001$ & 6 \\
\hline
\end{tabular}

The number of amide protons $\left(N_{1-3}\right)$ and their exchange rate constants $\left(k_{1-3}, h^{-1}\right)$ were determined by applying a 3-component model (eq 3 ) to deuterium exchange-in results, as illustrated in Figure 7 for the $53-63$ and $75-84$ segments of $\alpha A$-crystallin. one additional rapidly exchanging hydrogen in $\alpha \mathrm{A}^{75-85}$, it is evident that the amide hydrogen joining Asp 84 and Leu 85 exchanges rapidly. Similarly, segments $28-32$ and $28-34$ of $\alpha B$-crystallin are another pair of overlapping peptides. Analysis of the exchangein data for these two peptides (Table 1) indicates that amide hydrogens at Leu 33 and Glu 34 exchange slowly. One measure of the internal consistency of the method is indicated by the fact that the exchange-in data for both peptides (Table 1) give the same number of hydrogens with fast and intermediate exchange rates. The difference in the deuterium contents of $\alpha \mathrm{B}^{28-34}$ and $\alpha \mathrm{B}^{28-32}$ is plotted in Figure 8 versus the deuterium exchange-in time. The scatter in the data when the level of deuterium was around $10 \%$ is expected because the correction for artifactual deuterium exchange-in during digestion was also approximately $10 \%$. These data indicate that the average exchange rates for the amide hydrogens at Leu 33 and Glu 34 in the B-chain of $\alpha$-crystallin is approximately $0.007 \mathrm{~h}^{-1}$, which corresponds to a half-life of $99 \mathrm{~h}$. Since the maximum exchange-in time, $48 \mathrm{~h}$, was only about half of a half-life for the exchange of these amide hydrogens, it is not possible to determine from the linearity of the plot whether both hydrogens exchange at the same rate.

Whether digestion with pepsin gives overlapping peptides, or any peptides suitable for hydrogen exchange measurements, from specific regions of a protein depends primarily on the amino acid sequence in the region. For the digestion conditions used here, pepsin may cleave on the $\mathrm{C}$-terminal side of aspartic acid, glutamic acid, leucine, phenylalanine, tryptophan, and tyrosine. Regions devoid of these residues may be detected only as large fragments, which may exceed the practical mass limit of FABMS. Although large peptides with 20 to 40 residues may be detected, they are generally of less interest for hydrogen exchange measurements because of their associated low

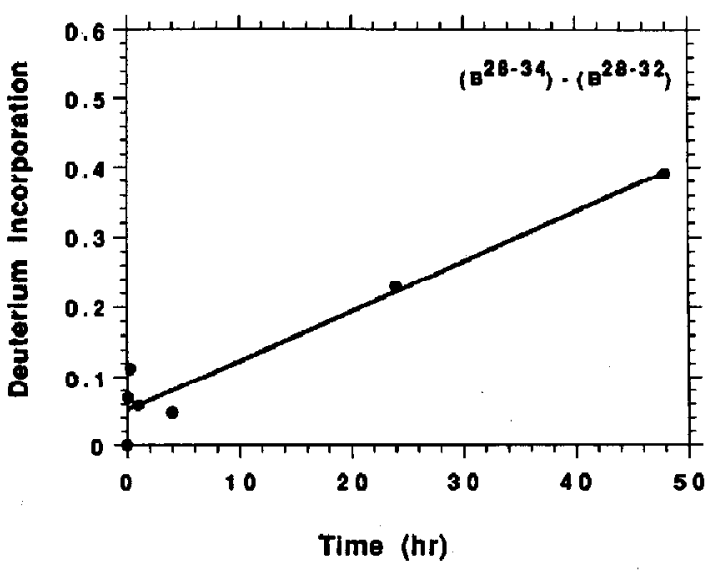

Figure 8. Plot of the difference in the deuterium levels in $\mathrm{aB}^{28-34}$ and $\alpha \mathrm{B}^{28-32}$ as a function of the time used for deuterium exchange-in. 
spatial resolution. For the digestion conditions described above, we have identified a family of peptides that permit accurate quantification of hydrogen exchange in approximately $50 \%$ of the backbones of $\alpha \mathrm{A}$ and $\alpha \mathrm{B}$-crystallins. Different approaches to generating new families of peptides are under investigation. These include small changes in $\mathrm{pH}$, different enzyme:substrate ratios, and use of other acid proteases, as described by Englander et al. [16].

\section{Hydrogen Exchange as a Probe of Conformational Change}

Conformational changes in proteins may alter hydrogen exchange rates by changing either the hydrogen bonding or the access of peptide amide hydrogens to the solvent. The total rate of hydrogen exchange in proteins has been used to indicate that conformational changes have occurred $[30,33]$. However, to understand the interplay of protein structure and function, it is important to know which regions within a protein participate in a conformational change. For example, Englander et al. [17] have recently demonstrated that hydrogen exchange can be used to determine the free energy change as specific regions in hemoglobin undergo conformational change.

Conformational changes in $\alpha$-crystallins are of particular interest because they may be an early step in cataractogenesis. To demonstrate that conformational changes in large proteins such as $\alpha$-crystallin aggregates can be detected and located by the experimental methods described above, we measured the deuterium levels in specific segments of $\alpha \mathrm{A}$-crystallin as a function of incubation temperature. Although the following results demonstrate that the temperature dependence of hydrogen exchange in large proteins can be determined by HPLC FABMS, interpreting the results requires special care. According to the localized unfolding model for amide hydrogen exchange [30], the rate constant for hydrogen exchange in proteins, $k_{e x}$, can be expressed as in eq 4

$$
\mathrm{k}_{\mathrm{cx}}=\mathrm{Kk}_{\mathrm{int}}
$$

where $\mathrm{K}$ is the equilibrium constant for momentary unfolding of a small segment of protein, and $\mathrm{k}_{\mathrm{int}}$ is the rate constant for hydrogen exchange in random structure peptides. According to this model, hydrogen exchange occurs only after a short segment of a protein unfolds, exposing the amide hydrogens to the solvent. When exposed to the solvent, the amide hydrogens undergo exchange at the rate indicated by $k_{\text {int }}$. To the extent that conformational changes in proteins alter $\mathrm{K}$, hydrogen exchange may be used as a probe of conformational change if the temperature dependence of $k_{\text {int }}$ is known. The rate constant for intrinsic hydrogen exchange, $\mathrm{k}_{\text {int }}$ can be calculated by adjusting the rate constant for amide hydrogen exchange in polyalanine for the inductive effects of adjacent side chains [31], $\mathrm{pH}$ (Figure 3), and temperature [11, 34].

The deuterium content at any peptide linkage is given by the expression:

$$
\mathrm{D}=1-\exp \left(-\mathbf{k}_{\mathrm{ex}} \mathrm{t}\right)=1-\exp \left(-\mathrm{Kk}_{\mathrm{int}} \mathrm{t}\right)
$$

where $k_{e x}$ is the determined rate constant for exchange, $k_{\text {int }}$ is the intrinsic rate constant for hydrogen exchange in peptides, $K$ is the equilibrium constant for unfolding of small segments of the protein prior to hydrogen exchange, and $t$ is the time the protein is incubated in $\mathrm{D}_{2} \mathrm{O}$. To emphasize the linkage between the deuterium content of the peptide and the temperature dependence of the unfolding process $(\mathrm{K})$, the linkage between the deuterium content of the peptide and the temperature dependence of the rate of intrinsic hydrogen exchange must be minimized. From eq 5 it is apparent that the exponent is linearly dependent on both $k_{\text {int }}$ and the incubation time, t. To visualize the temperature dependence of the unfolding process, represented by $K$, through the deuterium content of the peptide, the incubation time was adjusted to compensate for the temperature dependence of $k_{\text {int }}$ so that the product of $k_{\text {int }}$ and $t$ remained constant. The temperature dependence of $k_{\text {int }}$ was calculated from the activation energy $(17.4 \mathrm{Kcal} / \mathrm{mol})$ reported for hydrogen exchange in peptides [34]. For example, exchange-in times of 690 and $1.5 \mathrm{~min}$ were used for incubation temperatures of 10 and $80{ }^{\circ} \mathrm{C}$, respectively. This approach for emphasizing linkage between the deuterium content of peptides and the equilibrium constant for unfolding of the protcin could also be used to investigate unfolding as a function of $\mathrm{pH}$, ionic strength, and organic modifiers. It is therefore of general application.

The deuterium contents of two segments of $\alpha \mathrm{A}$ crystallin are illustrated in Figure 9 as the incubation temperature was increased from 10 to $80^{\circ} \mathrm{C}$. The increase in deuterium content of $\alpha \mathrm{A}^{32-37}$ with temperature reflects both the temperature dependence of hydrogen exchange in this segment and the thermal stability of the region of the protein in which this segment is located. Specifically, $\alpha \mathrm{A}^{32-37}$ is only $10 \%$ deuterated at $10^{\circ} \mathrm{C}$, suggesting that it is resistant to unfolding at this temperature. However, as the temperature used for deuterium exchange-in was increased to $80^{\circ} \mathrm{C}$, the deuterium level in $\alpha \mathrm{A}^{32}{ }^{37}$ increased to $60 \%$. According to the localized unfolding model of hydrogen exchange [30], this increased level of deuterium is a measure of the temperature stability of this region of the protein. Similar analysis of many other peptides derived from $\alpha$-crystallin suggests that the thermal stability of the protein is not uniform throughout (Liu, Y; Smith, D.L., unpublished observations).

Results for $\alpha A^{53-63}$ show that this segment is approximately $80 \%$ deuterated at the lowest temperature used for exchange-in. As the temperature was increased to $80{ }^{\circ} \mathrm{C}$, the deuterium level increased to approximately $95 \%$. Since this segment was highly 


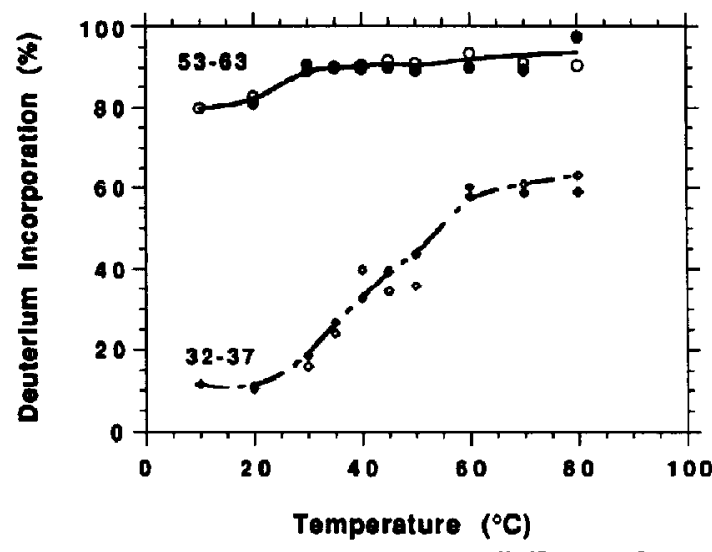

Figure 9. Deuterium incorporation into $\alpha \mathrm{A}^{32-37}$ and $\alpha \mathrm{A}^{53-63}$ of $\alpha$-crystallin as a function of incubation temperature. Incubation time was adjusted to compensate for the temperature dependence of the intrinsic rate of hydrogen exchange. Open and closed data points are results obtained for two different experiments performed several weeks apart.

deuterated at all temperatures, it is not a sensitive probe of the thermal stability of this region of $\alpha$-crystallin for the experimental conditions used in this study. However, it is noted that this segment might be a useful probe if a shorter deuterium exchange-in time were used.

The open and closed data points in Figure 9 represent data from two experiments that were performed several weeks apart. Despite the complexities of these measurements, including making adjustments for artifactual gain/loss during analysis, the results are highly reproducible.

\section{Conclusions}

Results of this study demonstrate that FABMS can be used to determine the rates at which hydrogen exchange occurs in short segments of large proteins. These results also demonstrate that a thermally induced conformational change within a small segment of a large protein can be detected. Given the established role of amide hydrogen exchange as a probe of the high order structure of proteins, these results suggest that the experimental methods described here have a potentially important role to play in studies aimed at relating the three-dimensional structure of proteins with their function. Although the protein fragmentation method for quantifying hydrogen exchange has been described previously [15, 16], this study demonstrates the feasibility of using hydrogen exchange as a general probe of high order structure of proteins that are too large to be studied by NMR spectroscopy. It may now be possible to use hydrogen exchange to localize conformational changes, to identify binding sites, and to determine structural homology (as opposed to sequence homology) in large proteins, just as NMR spectroscopy has been used for similar studies of very small proteins. The success of continuous-flow HPLC FABMS is due primarily to the fact that the deuterium content of peptides is determined on a short time scale relative to the time in which deuterium undergoes back-exchange. In addition, the format of FABMS data, moles of deuterium per molecule, is particularly useful because it facilitates direct calculation of the rate constants for hydrogen exchange.

\section{Acknowledgments}

This investigation was supported by grants GM RO1 40384 and EY RO1 07609 from the National Institutes of Health. The authors recognize Mr. Zhongqi Zhang for developing methods used in this investigation to analyze data from hydrogen exchange experiments.

\section{References}

1. Loo, J. A.; Ogorzalek, R. R.; Udseth, H. R.; Edmonds, C. G.; Smith, R. D. Rapid Commun. Mass Spectrom. 1991, 5, 101-105.

2. Katta, V.; Chait, B. I. Am. Chem. Soc. 1991, 113, 8534-8535.

3. Brown, C.; Camilleri, P.; Haskins, N. J.; Saunders, M. J. Chem. Soc., Chem. Commun. 1992, 1992, 761-764.

4. Katta, V.; Chait, B. Rapid Communt. Mass Spectrom. 1991, 5, 214-217.

5. Winger, B. E.; Light-Wahl, K. J.; Rockwood, A. L.; Smith, R. D. J. Am. Chem. Soc. 1992, 114, 5897-5898.

6. Roder, R.; Wagner, G.; Wüthrich, K. Biochemistry 1985, 24, 7396-7407.

7. Brandt, P.; Woodward, C. Biochemistry 1987, 26, 3156-3162.

8. Jeng, M. F.; Englander, S. W.; Elöve, G. A.; Wand, A. J.; Roder, H. Biochemistry 1990, 29, 10433-10437.

9. Paterson, Y.; Englander, S. W.; Roder, H. Science 1990, 249, 755-759.

10. Robertson, A. D; Baldwin, R. L. Biochemistry 1991, 30. 9907-9914.

11. Englander, S. W.; Poulsen, A. Biopolymers 1969, 7, 379-393.

12. Englander, S. W.; Englander, J. J. Methods Enzymol. 1978, 49, 24-39.

13. Muga, A.; Mantsch, H. H.; Surewicz, W. K. Biochemistry 1991, $30,7219-7224$.

14. Loftus, D.; Gbenle, G. O.; Kim. P. S.; Baldwin, R. L. Biochemistry 1986, 25, 1428-1436.

15. Rosa, J. J.; Richards, R. M. J. Mol. Biol. 1981, 145, 835-851.

16. Englander, J. J.; Rogero, J. R.; Englander, S. W. Anal. Biochem. 1985, 147, 234-244.

17. Englander, S. W., Englander, J. J.; McKinnie, R. E.; Ackers, G. K,; Turner, G. J.; Westrick, J. A.; Gill, S. J. Science 1992, 256. $1684-1687$.

18. Zhang, Z.; Smith, D. L. Protein Sci. 1993, 2, 522-531.

19. Smith, J. B.; Miesbauer, L. R.; Leeds, J.; Smith, D. L.; Loo, J. A.; Smith, R. D.; Edmonds, C. G. Int. I. Mass Spectrom. Ion. Processes 1992, 111, 229-245.

20. Smith, D. L. In Continuous-flow Fast Atom Bombardment Mass Spectrometry; Caprioli, F. M., Ed. Wiley: New York, 1990.

21. van der Ouderaa, R. J.; de Jong, W. W; Bloemendal, H. Exp. Eye Res. 1979, 28, 223-228.

22. van der Ouderaa, F. J.; de Jong, W. W.; Hilderink, A.; Bloemendal, H. Eur. J. Biochem. 1974, 49, 157-168.

23. Smith, J. B.; Thêvenon-Emeric, G.; Smith, D. L.; Green, B. Anal. Biochem. 1991, 193, 118-124.

24. Smith, J. B.; Sun, Y.; Smith, D. L.; Green, B. Protein Sci. 1992, $1,601-608$. 
25. Liang, J. N.; Chakrabarti, B. Biochemistry 1982, 21, 1847-1852. 26. Oetelaar, P. J. M, Someren, P. F, H. M.; Thomson, J. A.; Siezen, R. J.; Hoenders, H. J. Biochemistry 1990, 29, 3488-3493. 27. Schurtenberger, P.; Augusteyn, R. C. Biopolymers 1991, 31, 1229-1240.

28. Walsh, M. T.; Sen, A. C.; Chakrabarti, B.; I. Biol. Chem. 1991, $266,20079-20084$

29. Radlick, L. W.; Koretz, J. F. Biochim. Biophys. Acta 1992, 1120, $193-200$.
30. Englander, S. W.; Kallenbach, N. R. Quart. Rev. Biophys. 1984, $16,521-655$

31. Molday, R. S.; Englander, S. W.; Kallen, R. C. Biochemistry 1972, 11, 150-158.

32. Thévenon-Emeric, G.; Kozlowski, J.; Zhang, Z.; Smith, D. L. Anal. Chem. 1992, 64, 2456-2458.

33. Kaminsky, S. Mi; Richards, F. M. Protein Sci. 1992, 1, 10-21.

34. Englander, J. J.; Calhoun, D. B.; Englander, S. W. Anal. Biochem. 1979, 92, 517-524. 